\title{
The effect of compaction of the arable layer in sandy soils on the growth of maize for silage. 2. Soil conditions and plant growth
}

\author{
F. R. Boone ${ }^{1}$, H. M. G. van der Werf ${ }^{2}$, B. Kroesbergen ${ }^{1}$, B. A. ten $\operatorname{Hag}^{2}$ and A. \\ Boers $^{1}$ \\ 1 Soil Tillage Laboratory, Agricultural University, Diedenweg 20,6703 GW \\ Wageningen, Netherlands \\ 2 Research Station for Arable Farming and Field Production of Vegetables \\ (PAGV), P.O. Box 430, 8200 AK Lelystad, Netherlands
}

Received 12 November 1986; accepted 24 February 1987

Key words: soil compaction, maize, soil aeration, mechanical impedance

\begin{abstract}
The effect of different degrees of compaction of ploughed sandy soils on soil aeration and mechanical impedance, root growth and subsequent shoot growth was tested in five model field experiments. In a previous paper the potential effects of soil compaction on soil aeration and penetration resistance are described. In the present paper the actual field situations are analysed and crop responses discussed. Crop responses shifted considerably in the course of time due to crop growth and amount of rainfall. Final crop yield and soil density were related by optimum curves. Substantial yield reductions at severe compaction were caused by insufficient soil aeration. The approach to relate potential risks for root growth and root functioning of a range of soil structures to matric water potential seems promising in predicting risks for plant growth under specific circumstances.
\end{abstract}

\section{Introduction}

To obtain information about the range of soil structures which guarantees optimal maize production on sandy soils, the effect of compaction of ploughed soil on soil physical aspects, root and subsequent maize growth was tested in five model field experiments. Climate, especially rainfall, and specific site factors such as watertable depth in combination with soil structure, have a large impact on soil water and therefore on root growth factors. Under wet conditions soil aeration may become insufficient for the desired root growth and functioning of the root system. Under drier conditions root growth may be hampered by mechanical impedance which restricts the possibilities for uptake of water and ions and induces drought stress. The 
margin in soil conditions between too dry and too wet can be modified by soil structure. A previous paper (Boone et al., 1986) dealt with potential effects of different degrees of compaction of sandy soils on soil aeration and penetration resistance. A new approach towards critical matric water potentials in relation to both factors was proposed. The matric water potential continuously changes during the growing season, and the range of non-restrictive soil structures therefore depends on the expected level as well as on the variability in matric water potential. The narrower the range of matric water potentials which allow unimpeded root growth and functioning, the greater the potential risks for crop growth. The present paper analyses the actual soil conditions in the field experiments and discusses the responses in root and shoot growth. Finally, the critical matric water potential concept is tested in a preliminary way.

\section{Materials and methods}

\section{Soils and treatments}

Two experiments were on fine sand in Heino, one in 1980 and the other in 1982, two other experiments in 1981 on loamy fine sand in Heeten - Heeten H (High) and Heeten L (Low) - and one in Wijhe (1982) on fine sandy loam. Details are given by Boone et al. (1986). The soil in the Heino 1982 experiment had been grassland for three years. Water-table depth at compaction and sowing was $1.2 \mathrm{~m}$ in all experiments except in 1981: $1.7 \mathrm{~m}$ in Heeten $\mathrm{H}$ and $1.45 \mathrm{~m}$ in Heeten L. Liquid livestock manure was applied during winter and/or early spring. The soil was ploughed on about 1 May to a depth of $0.25 \mathrm{~m}$ and, except in Wijhe 1982, within three days the soil was compacted, the seed-bed prepared and the crop sown. The treatments were:

$\mathrm{L}=$ loose: not compacted

$\mathrm{CL}=$ compacted lightly: soil compacted with a packer at ploughing

$\mathrm{CM}=$ compacted moderately: compacted by driving once all over the soil with a tractor on double rear wheels

$\mathrm{CS}=$ compacted severely: compacted by driving three times all over the soil with a tractor on single rear wheels.

Maize (cv. Brutus) was sown with a precision drill at an accurately controlled depth of $0.05 \mathrm{~m}$ and a row distance of $0.75 \mathrm{~m}$. Phosphate, potassium and some nitrogen was side-dressed as starter fertilizer. Most nitrogen was wide-spread, in Heeten and in Wijhe at two levels (100 or 120 and 180 or $200 \mathrm{~kg} \mathrm{ha}^{-1}$, respectively). If necessary stands were thinned to a plant density of 9 plants per $\mathrm{m}^{2}$. All experiments were in triplicate except the one in 1980.

\section{Measurements}

Climate and soil conditions. Data on global radiation and air temperatures were obtained from the nearest meteo station, rainfall was measured on the site. Soil physical measurements were done during the greater part of the growing season. Watertable depths, gravimetric water contents, soil matric water potentials, soil oxygen 
concentrations and cone penetration resistances in different soil layers were determined at intervals of one week, or more frequently if thought necessary (for details see Boone et al., 1986).

Root and shoot growth. Root growth was measured three times during the growing season by counting the number of roots with a grid system of $0.05 \mathrm{~m} \times 0.05 \mathrm{~m}$ on vertical profile walls perpendicular to the row through the centre of 3 representative plants. In addition, in the Heino 1982 experiment, the roots have been analysed in more detail by sampling individual plants at emergence and 9 weeks later.

Plant emergence and the number of plants with Fritellaria were counted and sowing depth was measured in 6 rows of $8 \mathrm{~m}$ length. Crop appearance was estimated visually several times during the growing season. In 1982, shoot weight of 24 plants was determined in duplicate at two times. Anthesis was determined as the day $50 \%$ of the female flowers were flowering. Supposing that the total number of leaves was similar, plant senescence was estimated by counting the number of leaves with $50 \%$ or more green leaf surface area. Final yield parameters were determined on $30 \mathrm{~m}^{2}$ and included the number of lodged plants and plants with Fusarium, fresh and dry weight of stover and ear, crude fiber content, ash content, crude protein content and total nitrogen content. Aspects not mentioned in the results or discussion have not been significantly influenced by soil compaction.

\section{Results}

\section{Crop emergence}

Differences in sowing depths between treatments were insignificant. The number of days between sowing and $50 \%$ emergence differs considerably between but not within experiments (Table 1). There is a good linear relationship $(r=0.97)$ between the inverse of the number of days and the mean ambient air temperature indicating a minimum temperature for emergence of $7.3{ }^{\circ} \mathrm{C}$. Apparently, the temperature was the prime limiting factor for emergence rate. A moderately or severely compacted soil below sowing depth improved final emergence in 1980 by improving the supply of water to the seeds in a rainless period. The number of plants that

Table 1. Rainfall, mean air temperature, number of days between sowing and $50 \%$ emergence and number of plants per $\mathrm{m}^{2}$ before thinning relative to treatment CL.

\begin{tabular}{|c|c|c|c|c|c|c|c|c|}
\hline \multirow[t]{2}{*}{ Year } & \multirow[t]{2}{*}{ Soil } & \multirow{2}{*}{$\begin{array}{l}\text { Rainfall } \\
(\mathrm{mm})\end{array}$} & \multirow{2}{*}{$\begin{array}{l}\text { Temperature } \\
\left({ }^{\circ} \mathrm{C}\right)\end{array}$} & \multirow{2}{*}{$\begin{array}{l}\text { Time } \\
\text { (days) }\end{array}$} & \multicolumn{4}{|c|}{ Number of plants } \\
\hline & & & & & $\mathrm{CS}$ & $\mathrm{CM}$ & $\mathrm{CL}$ & $\mathrm{L}$ \\
\hline 1980 & FS & 4 & 10.8 & 16 & 116 & 114 & 9.8 & 103 \\
\hline 1981 & LFS(H) & 16 & 12.5 & 11 & 105 & 101 & 9.2 & 100 \\
\hline 1981 & LFS $(\mathrm{L})$ & 16 & 12.5 & 11 & 103 & 99 & 9.2 & 96 \\
\hline 1982 & FS & 36 & 10.3 & 20 & 100 & 103 & 8.8 & 101 \\
\hline 1982 & FSL & 32 & 11.2 & 13 & 103 & 107 & 9.1 & 97 \\
\hline
\end{tabular}


F. R. BOONE ET AL.

Table 2. General characteristics of the growing seasons.

\begin{tabular}{|c|c|c|c|c|c|}
\hline Year & Period & $\begin{array}{l}\text { Global radiation } \\
\left(\mathrm{KJ} \mathrm{cm}^{-2}\right)\end{array}$ & $\begin{array}{l}\text { Rainfall } \\
(\mathrm{mm})\end{array}$ & $\begin{array}{l}\text { Temp. } \\
\left({ }^{\circ} \mathrm{C}\right)\end{array}$ & $\begin{array}{l}\text { Duration } \\
\text { (days) }\end{array}$ \\
\hline \multirow[t]{3}{*}{1980} & emergence-anthesis & 117 & 254 & 14.4 & 77 \\
\hline & anthesis- 30 September & 53 & 111 & 15.9 & $75^{1}$ \\
\hline & total & 170 & 365 & 15.1 & 152 \\
\hline \multirow[t]{3}{*}{1981} & emergence-anthesis & 119 & 223 & 15.5 & 77 \\
\hline & anthesis-30 September & 79 & 82 & 16.1 & $75^{1}$ \\
\hline & total & 198 & 305 & 15.7 & 152 \\
\hline \multirow[t]{3}{*}{1982} & emergence-anthesis & $126 / 132^{2}$ & 145 & 17.2 & $63 / 66^{2}$ \\
\hline & anthesis-30 September & $96 / 92$ & 55 & 17.2 & $76 / 71^{1}$ \\
\hline & total & $222 / 224$ & 200 & 17.2 & $139 / 137$ \\
\hline
\end{tabular}

Table 3. Characteristics of periods distinguished within the growing seasons after emergence.

\begin{tabular}{lclll}
\hline Year & $\begin{array}{l}\text { Period } \\
\text { (day) }\end{array}$ & $\begin{array}{l}\text { global radiation } \\
\left(\mathrm{KJ} \mathrm{cm}^{-2} \mathrm{~d}^{-1}\right)\end{array}$ & $\begin{array}{l}\text { Rainfall } \\
\left(\mathrm{mm} \mathrm{d}^{-1}\right)\end{array}$ & $\begin{array}{l}\text { Temperature } \\
\left({ }^{\circ} \mathrm{C}\right)\end{array}$ \\
1980 & $0-34$ & 1.70 & 1.4 & 14.1 \\
& $35-64$ & 1.23 & 6.3 & 13.6 \\
& $65-135$ & 1.11 & 1.9 & 16.1 \\
1981 & $0-37$ & 1.69 & 2.0 & 14.7 \\
& $38-77$ & 1.50 & 4.3 & 16.1 \\
& $78-138$ & 1.32 & 1.4 & 16.1 \\
1982 & $0-24$ & 2.30 & & \\
& $25-44$ & 1.65 & 0.9 & 17.9 \\
& $45-135$ & 1.52 & $5.9 / 4.8^{1}$ & 14.8 \\
& & & 0.7 & 17.6 \\
\hline
\end{tabular}

${ }^{1}$ Heino/Wijhe.

emerged has been fully satisfactory in all experiments. Occasional differences between treatments were eliminated by thinning.

Growing season characteristics

The 1982 growing season was shorter than the 1980 and 1981 growing seasons mainly because the period between emergence and anthesis was shorter (Table 2). This coincided with a somewhat higher air temperature, a slightly higher global radiation and significantly less rain. After anthesis the 1980 growing season had more rain and less global radiation than the 1981 and, especially, the 1982 growing seasons.

In order to relate soil compaction with soil physical growth factors and subse- 
quent root and shoot growth, the growing seasons have been analysed in more detail, as summarized in the following paragraphs.

\section{Soil conditions, root and shoot growth in 1980}

The first 5 weeks after emergence had a relatively low temperature, a high global radiation and a low amount of rainfall (Table 3). Matric water potential at root depth was close to field capacity $\left(h_{\mathrm{m}}=-9 \mathrm{kPa}\right)$, oxygen concentration higher than $14 \%$ and cone resistance less than $1.5 \mathrm{MPa}$ in all treatments (Table 4). The depth above which $90 \%$ of all roots are found was in treatment CS $70 \%$ of that in treatment CL (Table 3 and Fig. 1). The crop showed a weak optimum at treatment CL.

Rainfall was very high during the next month, but radiation clearly and temperature slightly lower than in the first period. The water-table rose from -1.2 to $-1 \mathrm{~m}$ and the matric water potential in the arable layer periodically increased above -5 $\mathrm{kPa}$. Soil oxygen concentrations at root depth dropped to values below $5 \%$ in treatment CS. Root depth (90\% level: depth above which $90 \%$ of all roots are present) and especially the depth root density of $0.2 \mathrm{~cm}^{-2}$ (one root per $5 \mathrm{~cm}^{2}$ ) was

Table 4. Typical soil and crop characteristics after emergence on 18 May 1980 (Heino).

\begin{tabular}{|c|c|c|c|c|c|c|}
\hline \multirow{2}{*}{$\begin{array}{l}\text { Period } \\
\text { (day) }\end{array}$} & & \multirow{2}{*}{$\begin{array}{l}\text { Depth } \\
\text { (cm) }\end{array}$} & \multicolumn{4}{|c|}{ Treatment } \\
\hline & & & $\mathrm{CS}$ & $\mathrm{CM}$ & $\mathrm{CL}$ & $\mathrm{L}$ \\
\hline \multirow[t]{6}{*}{$0-34$} & Matric water potential (-kPa) & 15 & \multicolumn{2}{|c|}{$7-11$} & \multicolumn{2}{|l|}{$7-11$} \\
\hline & Oxygen concentration $(\%)$ & 15 & 14 & 18 & 20 & $>20$ \\
\hline & & 35 & 10 & 16 & 19 & 20 \\
\hline & Cone resistance (MPa) & 15 & 1.1 & 0.7 & 0.5 & 0.6 \\
\hline & Root depth $(90 \%)$ day $24(\mathrm{~cm})$ & & 9 & 11 & 13 & . \\
\hline & Crop appearance day $24(0-10)^{*}$ & & 6.5 & 6.8 & 7.5 & 7.3 \\
\hline \multirow[t]{7}{*}{$35-64$} & Matric water potential $(-\mathrm{kPa})$ & 15 & 5 & . & 5 & . \\
\hline & & 35 & 3 & . & 3 & . \\
\hline & Oxygen concentration $(\%)$ & 15 & 7 & 9 & 16 & . \\
\hline & & 35 & 3 & 9 & 18 & . \\
\hline & Root depth $(90 \%)$ day $47(\mathrm{~cm})$ & & 18 & 24 & 24 & 25 \\
\hline & Root density $0.2 \mathrm{~cm}^{-2}$ day $47(\mathrm{~cm})$ & & 9 & 24 & 22 & 25 \\
\hline & Crop appearance day $47(0-10)^{*}$ & & 7.0 & 7.8 & 8.0 & 6.5 \\
\hline \multirow[t]{10}{*}{$65-152$} & Oxygen concentration day $67(\%)$ & 15 & 19 & 16 & 17 & $>20$ \\
\hline & & 35 & 17 & 20 & 18 & $>20$ \\
\hline & & 75 & 14 & 19 & $>20$ & $>20$ \\
\hline & Anthesis (day) & & 79 & 77 & 77 & 77 \\
\hline & Root depth $(90 \%)$ day $102(\mathrm{~cm})$ & & 12 & . & 23 & . \\
\hline & Root density $0.2 \mathrm{~cm}^{-2}$ day $102(\mathrm{~cm})$ & & 14 & . & 27 & . \\
\hline & Leaves per plant $>50 \%$ green day 121 & & 6.9 & 9.4 & 10.1 & 10.2 \\
\hline & Dry matter yield $\left(\mathrm{t} \mathrm{ha}^{-1}\right)$ & & 11.9 & 14.4 & 14.4 & 14.2 \\
\hline & Dry matter content whole plant $(\%)$ & & 30.6 & 30.8 & 30.4 & 29.4 \\
\hline & Ear in dry matter $(\%)$ & & 51.6 & 54.2 & 53.1 & 52.4 \\
\hline
\end{tabular}

* $0=$ very bad, $10=$ very good. 


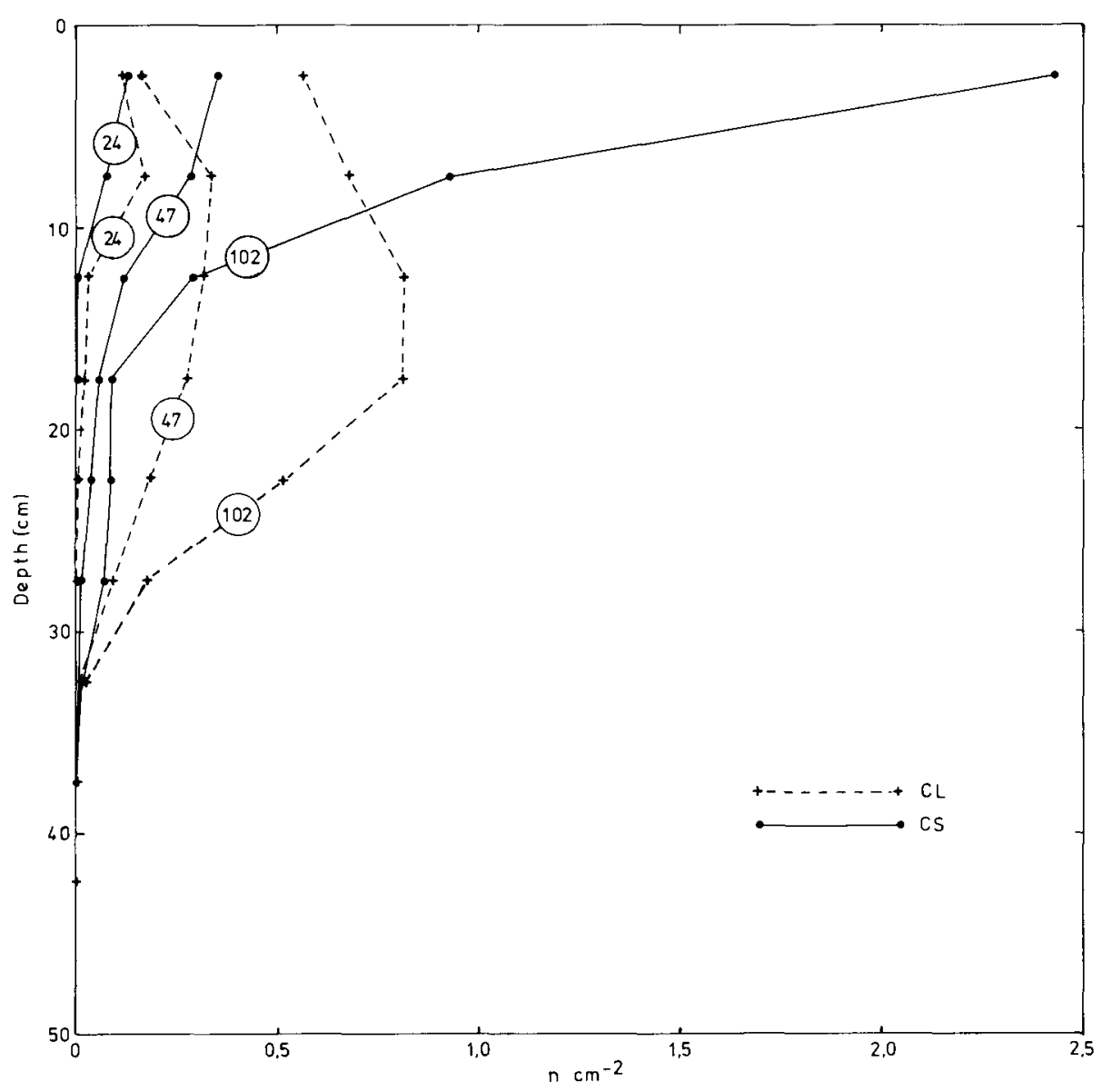

Fig. 1. Distribution of roots counted on vertical profile walls with depth in treatments CL and CS of Heino 1980 on 24,47 and 102 days after emergence.

much less in treatment CS than in treatment $C L$. This indicates that aeration of the root system was suboptimal. Crop appearance in the middle of this wet period was still better in treatment $C L$ than in treatment CS and treatment $\mathrm{L}$. In the last week of this period, especially in treatment CS, leaf colour changed from dark green to light green.

The third period had some rain every now and then, radiation initially increased and the temperature was somewhat higher than in the preceding period. Soil water content decreased and soil aeration in treatment CS improved very rapidly. Anthesis occurred shortly after the wet second period but was two days later in treatment CS than in the other treatments. Five weeks later it appeared that the total number of roots was similar but the distribution still quite different between treatments. 
The $0-0.05 \mathrm{~m}$ layer in treatment CS contained $62 \%$ and in treatment CL only $16 \%$ of all roots (Fig. 1). Crop senescence started earlier in treatment CS than in the other treatments. Total dry matter yield at harvest was $17 \%$ less in treatment CS than in the other treatments.

\section{Soil conditions, root and shoot growth in 1981}

The first five weeks of the growing season were characterized by moderate temperatures, high global radiation and with some rainfall only during the first two weeks. Matric water potential at root depth was slightly less than field capacity especially in part $\mathrm{H}$ of the experimental field (Tables 5 and 6). Soil oxygen concentrations in treatment CS were about $10 \%$ at emergence, but gradually improved with time, whereas cone resistance steadily increased from 1.3 to $2 \mathrm{MPa}$. Root depth $(90 \%$ level) was less the more the soil was compacted. Root depth in treatment CS was 58 and $81 \%$ of treatment $\mathrm{CL}$, on part $\mathrm{H}$ and part $\mathrm{L}$ respectively. Crop appearance in

Table 5. Typical soil and crop characteristics after emergence on 15 May 1981 (Heeten H).

\begin{tabular}{|c|c|c|c|c|c|c|}
\hline \multirow{2}{*}{$\begin{array}{l}\text { Period } \\
\text { (day) }\end{array}$} & & \multirow{2}{*}{$\begin{array}{l}\text { Depth } \\
(\mathrm{cm})\end{array}$} & \multicolumn{4}{|c|}{ Treatment } \\
\hline & & & CS & $\mathrm{CM}$ & $\mathrm{CL}$ & $\mathbf{L}$ \\
\hline \multirow[t]{6}{*}{$0-37$} & Matric water potential (-kPa) & 15 & $8-25$ & . & $8-25$ & . \\
\hline & Oxygen concentration $(\%)$ & 15 & 11 & 18 & 20 & . \\
\hline & & 35 & 9 & 17 & 19 & \\
\hline & Cone resistance $(\mathrm{MPa})$ & 15 & 1.6 & 1.1 & 0.7 & 0.8 \\
\hline & Root depth $(90 \%)$ day $26(\mathrm{~cm})$ & & 11 & 13 & 19 & 22 \\
\hline & Crop appearance day $32(0-10)^{*}$ & & 7.9 & 7.4 & 6.2 & 5.9 \\
\hline \multirow[t]{7}{*}{$38-77$} & Matric water potential $(-\mathrm{kPa})$ & 15 & $9-18$ & . & $8-18$ & \\
\hline & & 35 & $8-12$ & & $9-12$ & . \\
\hline & Oxygen concentration $(\%)$ & 15 & 12 & 16 & 19 & . \\
\hline & & 35 & 8 & 18 & 19 & . \\
\hline & Root depth $(90 \%)$ day $52(\mathrm{~cm})$ & & 24 & - & 28 & 30 \\
\hline & Root density $0.2 \mathrm{~cm}^{-2}$ day $52(\mathrm{~cm})$ & & 13 & . & 20 & 23 \\
\hline & Crop appearance day $59(0-10)^{*}$ & & 7.7 & 8.5 & 7.5 & 6.4 \\
\hline \multirow[t]{12}{*}{$78-152$} & Oxygen concentration day $85(\%)$ & 15 & 17 & 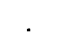 & . & . \\
\hline & & 35 & 14 & 18 & . & . \\
\hline & & 60 & 14 & . & . & . \\
\hline & Anthesis (day) & & 76 & 74 & 78 & 79 \\
\hline & Root depth $(90 \%)$ day $105(\mathrm{~cm})$ & & 40 & . & 36 & 30 \\
\hline & Root density $0.2 \mathrm{~cm}^{-2}$ day $105(\mathrm{~cm})$ & & 30 & . & 35 & 37 \\
\hline & Crop appearance day $110(0-10)^{*}$ & & 8.2 & 8.8 & 9.1 & 8.9 \\
\hline & Leaves per plant $>50 \%$ green day 124 & & 8.9 & 9.5 & 9.5 & 10.0 \\
\hline & Leaves per plant $>50 \%$ green day 152 & & 1.5 & 2.6 & 2.6 & 2.7 \\
\hline & Dry matter yield ( $\left.\mathrm{t} \mathrm{ha}^{-1}\right)$ & & 14.4 & 15.3 & 15.1 & 14.9 \\
\hline & Dry matter content whole plant $(\%)$ & & 32.2 & 30.4 & 29.0 & 28.5 \\
\hline & Ear in dry matter $(\%)$ & & 56.4 & . & 54.1 & . \\
\hline
\end{tabular}

* $0=$ very bad, $10=$ very good. 
F. R. BOONE ET AL.

Table 6. Typical soil and crop characteristics after emergence on 15 May 1981 (Heeten L).

\begin{tabular}{|c|c|c|c|c|c|c|}
\hline \multirow{2}{*}{$\begin{array}{l}\text { Period } \\
\text { (day) }\end{array}$} & & \multirow{2}{*}{$\begin{array}{l}\text { Depth } \\
(\mathrm{cm})\end{array}$} & \multicolumn{4}{|c|}{ Treatment } \\
\hline & & & CS & $\mathrm{CM}$ & $\mathrm{CL}$ & $\mathbf{L}$ \\
\hline \multirow[t]{6}{*}{$0-37$} & Matric water potential $(-\mathrm{kPa})$ & 15 & $9-17$ & & $8-15$ & . \\
\hline & Oxygen concentration (\%) & 15 & 11 & 19 & 19 & . \\
\hline & & 35 & 11 & 18 & 18 & \\
\hline & Cone resistance (MPa) & 15 & 1.7 & 1.0 & 0.8 & 0.8 \\
\hline & Root depth $(90 \%)$ day $26(\mathrm{~cm})$ & & 13 & & 16 & \\
\hline & Crop appearance day $32(0-10)^{*}$ & & 7.4 & 7.2 & 6.4 & 5.4 \\
\hline \multirow[t]{7}{*}{$38-77$} & Matric water potential $(-\mathrm{kPa})$ & 15 & $6-18$ & . & $5-11$ & \\
\hline & & 35 & $4-7$ & & 3-8 & \\
\hline & Oxygen concentration (\%) & 15 & 8 & 18 & 19 & . \\
\hline & & 35 & 5 & 16 & 16 & \\
\hline & Root depth $(90 \%)$ day $52(\mathrm{~cm})$ & & 16 & 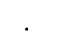 & 28 & 28 \\
\hline & Root density $0.2 \mathrm{~cm}^{-2}$ day $52(\mathrm{~cm})$ & & 12 & & 22 & 26 \\
\hline & Crop appearance day $59(0-10)^{*}$ & & 5.9 & 7.2 & 7.2 & 6.4 \\
\hline \multirow[t]{12}{*}{$78-152$} & Oxygen concentration day $85(\%)$ & 15 & 15 & & & \\
\hline & & 35 & 12 & 17 & 17 & \\
\hline & & 60 & 12 & & 15 & \\
\hline & Anthesis (day) & & 76 & 78 & 77 & 80 \\
\hline & Root depth $(90 \%)$ day $105(\mathrm{~cm})$ & & 26 & . & 30 & 32 \\
\hline & Root density $0.2 \mathrm{~cm}^{-2}$ day $105(\mathrm{~cm})$ & & 30 & & 33 & 36 \\
\hline & Crop appearance day $110(0-10)^{*}$ & & 4.6 & 7.5 & 8.1 & 8.0 \\
\hline & Leaves per plant $>50 \%$ green day 124 & & 7.2 & 9.5 & 9.9 & 10.0 \\
\hline & Leaves per plant $>50 \%$ green day 152 & & 0.8 & 2.3 & 2.7 & 2.7 \\
\hline & Dry matter yield $\left(\mathrm{t} \mathrm{ha}^{-1}\right)$ & & 12.2 & 13.6 & 14.9 & 14.5 \\
\hline & Dry matter content whole plant (\%) & & 32.2 & 30.0 & 29.1 & 28.4 \\
\hline & Ear in dry matter $(\%)$ & & 54.7 & & 53.2 & \\
\hline
\end{tabular}

* $0=$ very bad, $10=$ very good.

this period, however, was better the more the soil was compacted. Crop appearance was slightly better in part $\mathrm{H}$ than in part $\mathrm{L}$.

The next 5.5 weeks were wet and dominated by 5 days with high amounts of rainfall (18-38 mm) with intervals of 1-10 days. The water-table rose from -1.7 to -1.5 $\mathrm{m}$ in part $\mathrm{H}$ and from -1.45 to $-1.30 \mathrm{~m}$ in part $\mathrm{L}$. The matric water potential in the arable layer temporarily increased to field capacity in part $\mathrm{H}$ and to matric water potentials close to $-5 \mathrm{kPa}$ in part $\mathrm{L}$. Soil oxygen concentrations at root depth in treatment CS steadily dropped to $5 \%$ in part $\mathrm{L}$ and to $8 \%$ in part $\mathrm{H}$. Mechanical resistance was less than during the first period, but root depth $(90 \%$ level) in treatment CS already 2 weeks after the beginning of the wet period, was $86 \%$ and $57 \%$ of treatment $\mathrm{CL}$ in part $\mathrm{H}$ and $\mathrm{L}$, respectively. The same tendency was found for the root density. Contrary to the first period, now root growth in treatment CS was more impaired in part $\mathrm{L}$ than in part $\mathrm{H}$. This is another indication that soil aeration 
in treatment CS has been suboptimal in part $\mathrm{L}$. Crop growth in this period was hampered in treatment CS, especially in part $\mathrm{L}$ in which also treatment $\mathrm{CM}$ was negatively affected. Consequently, crop appearance in relation to compaction shifted towards an optimum at treatment $\mathrm{CM}$ in part $\mathrm{H}$ and between treatments $\mathrm{CM}$ and $\mathrm{CL}$ in part $\mathrm{L}$. Anthesis near the end of the wet second period was 1-2 days earlier in treatment $C S$ and 1-2 days later in treatment $L$ than in treatment $C L$.

The last part of the growing season had less rain than normal (about $2 \mathrm{~mm} \mathrm{~d}^{-1}$ ), the first three weeks were even without any rain. Global radiation and temperature were moderate. Soil aeration in treatment CS improved rapidly. Because the water-table was maintained at about $-1.8 \mathrm{~m}$ in part $\mathrm{H}$ and at about $-1.6 \mathrm{~m}$ in part $\mathrm{L}$, matric water potential at $35 \mathrm{~cm}$ depth in September was still $-13 \mathrm{kPa}$ and $-9 \mathrm{kPa}$ in part $\mathrm{H}$ and L, respectively. The total number of roots in treatment CS was 75 and $71 \%$ of the mean of treatments $\mathrm{CL}$ and $\mathrm{L}$ in part $\mathrm{H}$ and $\mathrm{L}$, respectively. Root depth $(90 \%)$ tended to be greater in part $\mathrm{H}$ than in part $\mathrm{L}$ and was smallest in treatment CS of part L. The depth root density, $0.2 \mathrm{~cm}^{-2}$, was the same in part $\mathrm{H}$ and $\mathrm{L}$ and only slightly smaller than in other treatments. The clearest accumulation of roots at

Table 7.Typical soil and crop characteristics after emergence on 18 May 1982 (Heino).

\begin{tabular}{|c|c|c|c|c|c|c|}
\hline \multirow{2}{*}{$\begin{array}{l}\text { Period } \\
\text { (day) }\end{array}$} & & \multirow{2}{*}{$\begin{array}{l}\text { Depth } \\
(\mathrm{cm})\end{array}$} & \multicolumn{4}{|c|}{ Treatment } \\
\hline & & & $\mathrm{CS}$ & $\mathrm{CM}$ & $\mathrm{CL}$ & $\mathrm{L}$ \\
\hline \multirow[t]{7}{*}{$0-24$} & Matric water potential $(-\mathrm{kPa})$ & 15 & $8-23$ & & $8-25$ & . \\
\hline & Oxygen concentration day $0(\%)$ & 15 & 6 & 17 & 19 & \\
\hline & day 22 & 15 & 19 & 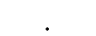 & & \\
\hline & Cone resistance $(\mathrm{MPa})$ & 15 & 1.6 & 1.1 & 0.7 & 0.6 \\
\hline & Root depth $(90 \%)$ day $20(\mathrm{~cm})$ & & 10 & 11 & 15 & 14 \\
\hline & Crop appearance day $8(0-10)^{*}$ & & 6.2 & 6.9 & 7.3 & 7.4 \\
\hline & Shoot dry weight $(\mathrm{g})$ per plant day 20 & & 3.0 & 3.0 & 2.6 & 1.9 \\
\hline \multirow[t]{5}{*}{$25-44$} & Matric water potential $(-\mathrm{kPa})$ & 15 & 5 & . & 5 & . \\
\hline & & 35 & 4 & & 4 & \\
\hline & Oxygen concentration (\%) & 15 & 6 & 15 & 17 & . \\
\hline & & 35 & 3 & 12 & 16 & \\
\hline & Crop appearance day $36(0-10)^{*}$ & & 7.8 & 8.2 & 7.3 & 6.6 \\
\hline \multirow[t]{11}{*}{$45-138$} & Root depth $(90 \%)$ day $51(\mathrm{~cm})$ & & 20 & 25 & 27 & 28 \\
\hline & Root density $0.2 \mathrm{~cm}^{-2}$ day $51(\mathrm{~cm})$ & & 22 & 28 & 30 & 32 \\
\hline & Shoot dry weight $(\mathrm{g})$ per plant day 51 & & 50 & 57 & 54 & 45 \\
\hline & Anthesis (day) & & 63 & 63 & 64 & 64 \\
\hline & Root depth $(90 \%)$ day $109(\mathrm{~cm})$ & & 36 & & 38 & \\
\hline & Root density $0.2 \mathrm{~cm}^{-2}$ day $109(\mathrm{~cm})$ & & 33 & & 34 & \\
\hline & Crop appearance day $99(0-10)^{*}$ & & 7.7 & 8.9 & 8.5 & 8.7 \\
\hline & Shoot dry weight (g) per plant day 114 & & 201 & 228 & 225 & 213 \\
\hline & Dry matter yield $\left(\mathrm{tha}^{-1}\right)$ & & 16.6 & 17.7 & 18.0 & 17.7 \\
\hline & Dry matter content whole plant (\%) & & 33.9 & 32.5 & 33.1 & 32.5 \\
\hline & Ear in dry matter $(\%)$ & & 61.5 & . & . & 60.4 \\
\hline
\end{tabular}

* $0=$ very bad; $10=$ very good. 
the interface of the loose arable layer of treatment $\mathrm{L}$ and the dense subsoil was observed in part $\mathrm{H}$. The $0-0.05 \mathrm{~m}$ layer in treatment $\mathrm{CS}$ contained 26 and $32 \%$ and in treatment $\mathrm{CL} 17$ and $16 \%$ of all roots in part $\mathrm{H}$ and $\mathrm{L}$, respectively. Crop appearance in early September showed in part $\mathrm{H}$ a weak optimum at treatment $\mathrm{CL}$ and a clear difference between treatments $C S$ and $C L$. Figures in part $L$ of treatments $C L$ and $\mathrm{L}$ are somewhat, those of treatment $\mathrm{CM}$ clearly and those of treatment CS considerably lower than in part $\mathrm{H}$. Crop senescence started earliest in treatment CS, especially in part $\mathrm{L}$ where treatment $\mathrm{CM}$ was affected as well. Total dry matter yield at harvest in part $\mathrm{H}$ shows a weak optimum at treatment $\mathrm{CM}$ with a statistically significant $6 \%$ difference between treatments CS and CM. Highest yields in part $\mathrm{L}$ were reached in treatment $\mathrm{CL}$. The difference between treatments $\mathrm{CM}$ and $\mathrm{CL}$ is $8 \%$ and between treatments CS and CL $18 \%$, which is significant. The effect of extra nitrogen is not significant. Dry matter content of the whole plant and the percentage of ear in the total dry matter slightly increased with compaction.

Table 8. Typical soil and crop characteristics after emergence on 18 May 1982 (Wijhe).

\begin{tabular}{|c|c|c|c|c|c|c|}
\hline \multirow{2}{*}{$\begin{array}{l}\text { Period } \\
\text { (day) }\end{array}$} & & \multirow{2}{*}{$\begin{array}{l}\text { Depth } \\
\text { (cm) }\end{array}$} & \multicolumn{4}{|c|}{ Treatment } \\
\hline & & & $\overline{\mathrm{CS}}$ & $\mathrm{CM}$ & $\mathrm{CL}$ & $\mathrm{L}$ \\
\hline \multirow[t]{6}{*}{$0-24$} & Matric water potential $(-\mathrm{kPa})$ & 15 & $8-80$ & & $7-56$ & r. \\
\hline & Oxygen concentration day $0(\%)$ & 15 & 17 & 18 & 20 & . \\
\hline & day 22 & 15 & 20 & . & & \\
\hline & Cone resistance $(\mathrm{MPa})$ & 15 & 2.9 & 2.2 & 0.9 & 0.8 \\
\hline & Crop appearance day $15(0-10)^{*}$ & & 7.6 & 7.9 & 6.8 & 6.8 \\
\hline & Shoot dry weight (g) per plant day 23 & & 3.1 & 3.6 & 2.0 & 1.6 \\
\hline \multirow[t]{5}{*}{$25-44$} & Matric water potential $(-\mathrm{kPa})$ & 15 & 5 & . & 7 & . \\
\hline & & 35 & 4 & & 5 & . \\
\hline & Oxygen concentration (\%) & 15 & 11 & 14 & 19 & . \\
\hline & & 35 & 7 & 12 & 18 & \\
\hline & Crop appearance day $43(0-10)^{*}$ & & 7.9 & 8.7 & 8.0 & 7.7 \\
\hline \multirow[t]{10}{*}{$45-138$} & Root depth $(90 \%)$ day $55(\mathrm{~cm})$ & & 27 & . & 29 & . \\
\hline & Root density $0.2 \mathrm{~cm}^{-2}$ day $55(\mathrm{~cm})$ & & 30 & - & 33 & 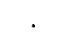 \\
\hline & Shoot dry weight $(\mathrm{g})$ per plant 58 & & 71 & 78 & 67 & 54 \\
\hline & Anthesis (day) & & 65 & 64 & 66 & 66 \\
\hline & Root depth $(90 \%)$ day $109(\mathrm{~cm})$ & & 36 & . & 38 & . \\
\hline & Root density $0.2 \mathrm{~cm}^{-2}$ day $109(\mathrm{~cm})$ & & 37 & & 40 & \\
\hline & Crop appearance day $99(0-10)^{*}$ & & 7.7 & 8.3 & 8.1 & 8.2 \\
\hline & Dry matter yield ( $\left.\mathrm{tha}^{-1}\right)$ & & 15.7 & 16.7 & 16.6 & 16.1 \\
\hline & Dry matter content whole plant (\%) & & 34.6 & 33.3 & 32.8 & 32.4 \\
\hline & Ear in dry matter $(\%)$ & & 60.9 & . & 62.7 & . \\
\hline
\end{tabular}

* $0=$ very bad and $10=$ very good. 


\section{Soil conditions, root and shoot growth in 1982}

Early sowing in Heino in a cold soil delayed emergence. Some emerging shoots in treatment CS had a light colour, and one week after emergence plants still looked somewhat better in treatments $\mathrm{CL}$ and $\mathrm{L}$ than in treatment CS (Table 7). Sowing one week later in Wijhe in a warmer and drier seedbed accelerated emergence so much that plants emerged on the same day as in Heino.

The first three weeks of the growing season had a relatively high temperature, a high global radiation and a low amount of rain. At emergence soil oxygen concentration in treatment CS in Heino was only $6 \%$ but rapidly increased as matric water potential gradually decreased. Root growth occurred at (Heino) or near (Wijhe) field capacity. Cone resistance in treatment CS increased to 1.6 and $2.9 \mathrm{MPa}$ in $\mathrm{Hei}-$ no and Wijhe respectively. In Heino root depth and the total number of roots in treatment CS were about $70 \%$ of those in treatment CL. Shoot dry weight in treatments CS and CM, however, were 14 and $15 \%$ higher than in treatment CL and 62 and $63 \%$ higher than in treatment L. Differences in Wijhe were even larger. Shoot dry weight of treatments $\mathrm{CS}$ and $\mathrm{CM}$ were 59 and $85 \%$ higher respectively than those of treatment CL and 97 and $130 \%$ higher than those of treatment L.

The next 3 weeks were wet, especially in Heino. The water-table rose from -1.3 to $-0.95 \mathrm{~m}$ in Heino and from -1.3 to $-1.15 \mathrm{~m}$ in Wijhe. The matric water potential in the arable layer increased to about $-5 \mathrm{kPa}$ in both experiments (Fig. 2). Soil oxygen concentrations at root depth in treatment CS decreased to 3 a $6 \%$ in Heino (Fig. 2) and to 7 a $11 \%$ in Wijhe. Root depth $\left(90 \%\right.$, root density $\left.0.2 \mathrm{~cm}^{-2}\right)$ in treatment CS of Heino shortly after this wet period was $75 \%$ of the depth in treatment $\mathrm{CL}$, but the total number of roots was similar. The $0-0.05 \mathrm{~m}$ layer contained 46 and $18 \%$, respectively, of all roots. Shoot dry weight was highest in treatment $\mathrm{CM}$ and 14,6 and $27 \%$ lower in treatments CS, CL and L respectively. Root depth and total number of roots in Wijhe were similar in treatments CS and CL. The 0-0.05 m layer contained 36 and $11 \%$, respectively, of all roots. Shoot dry weight shows an optimum at treatment $\mathrm{CM}$ and is 9,16 and $44 \%$ lower in treatments CS, CL and L respectively.

The third part of the growing season had clearly less rain than normal, the first 5 weeks were even without rain of any importance. Global radiation and temperature were moderately high in July and gradually decreased in August and September. Soil aeration in treatment CS in Heino improved rapidly. The water-table gradually fell to $-1.6 \mathrm{~m}$ in Heino and to $-1.4 \mathrm{~m}$ in Wijhe and was constant later on. Mechanical resistance in treatments CS increased considerably. Two weeks after the wet period already values of 2.2 and 4.3 MPa were measured at a depth of $15 \mathrm{~cm}$ in Heino and Wijhe, respectively. Anthesis occurred about 3 weeks after the second period, in Wijhe one day earlier in treatment CS and two days earlier in treatment $\mathrm{CM}$ and in Heino 0.5 day later in treatment $\mathrm{L}$ than in treatment CL. The total number of roots in Heino was similar in treatments CS and CL but treatment CS in Wijhe had only $68 \%$ of the roots in treatment CL. Root depths were similar in both experiments and treatments. Crop appearance and shoot dry weight in Heino reveal a weak optimum at treatment $\mathrm{CM}$ and 13 and $7 \%$ lower values for treatments $\mathrm{CS}$ and L respectively. Differences between treatments in Wijhe were smaller. 


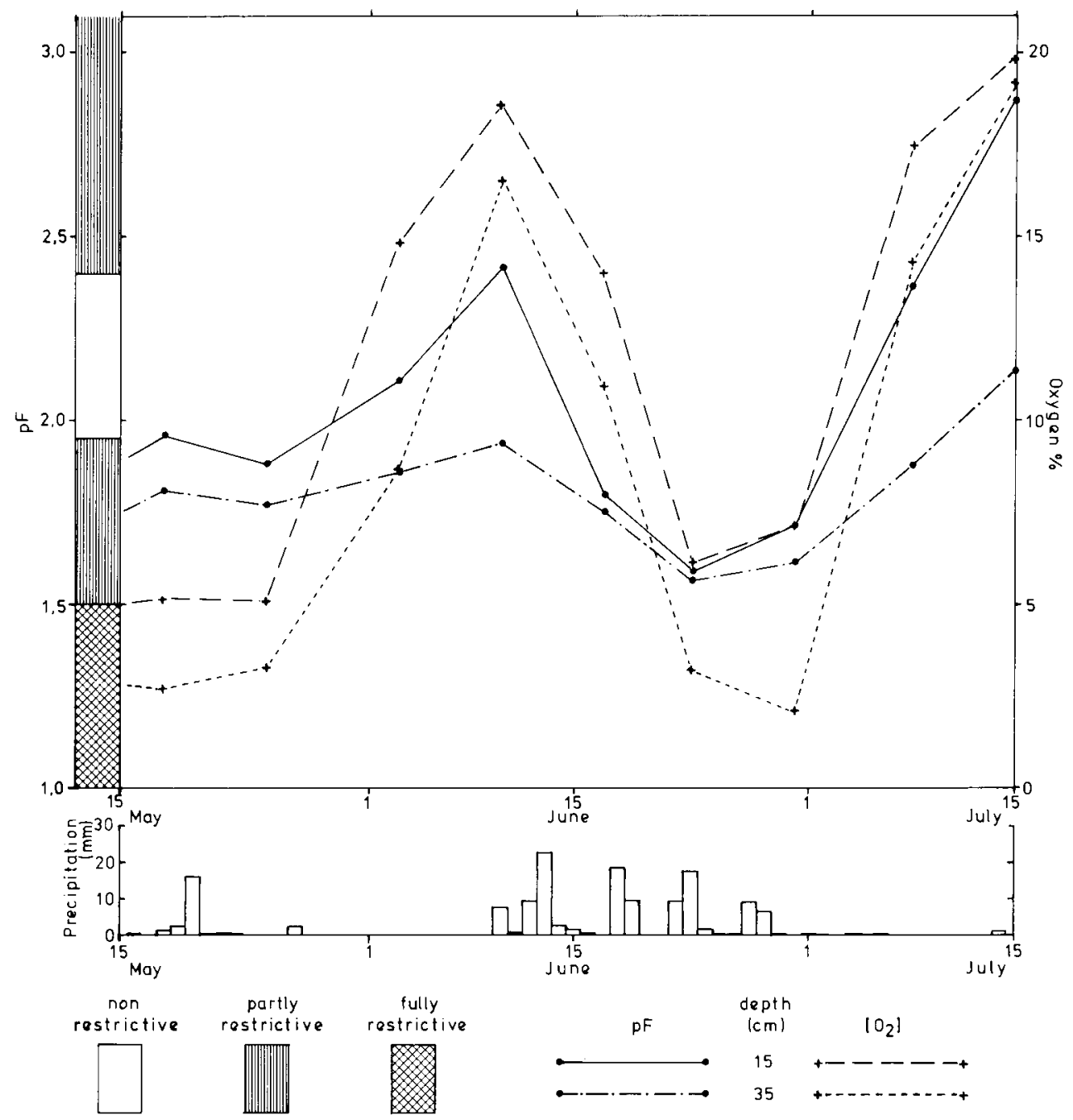

Fig. 2. Measured matric water potentials and oxygen concentrations in treatment CS of Heino 1982. Left bar indicates range of non-restrictive, partly and fully restrictive matric water potentials for root growth based on gas diffusion coefficients and penetration resistances.

There were no clear differences in crop senescence between treatments in both experiments. Total dry matter yields at harvest show weak optima. Treatment CS in Heino had a significant $8 \%$ lower yield than treatment CL. Differences in Wijhe are not significant. The effect of extra nitrogen is also not significant. Dry matter contents and ear percentages in dry matter show small and inconsistent differences. 


\section{Discussion}

At crop emergence the arable layer was at field capacity and soil aeration was sufficient in all treatments although just sufficient in the severely compacted soil which had been grassland and, as published in a previous paper (Boone et al., 1986), had a high oxygen consumption. During the first part of each growing season rainfall was less than evapotranspiration and soil water gradually decreased, increasing mechanical impedance in the most compacted soil to intermediate values. As a consequence the root growth rate was less than in less compacted soil. Despite the smaller root systems on the moderately and severely compacted treatments, early crop growth in 3 out of 5 experiments was even favoured by soil compaction. Only in 1980 a different trend was observed in favour of the non-compacted or lightly compacted soil. In this year probably a low soil temperature was the prime-rate limiting factor for early crop growth. Soil compaction increased capillarity, which reduced the warming up of the soil at the growing point of maize, just above sowing depth. In Heino 1982 early sowing delayed emergence in all treatments. Air temperature rose shortly after emergence but soil temperature in compacted soil probably increased at a slower rate accounting for a less rapid shoot growth during the first week. Later on the crop responded gradually in favour of the compacted soil which is also in line with the experiment in Wijhe during the same growing season. The soil matric water potential decreased in 1981 and 1982 more than in 1980 and the positive relation between soil compaction and crop growth therefore is probably due to a better water availability in compacted soil. This availability might have been improved by an easier soil water transport as well as by an improved root-soil contact. Recent preliminary results (work in progress of F. R. Boone, M. J. Kooistra, M. van Noordwijk and B. W. Veen) show that mean root-soil contact increased from 67 to $99 \%$ of the root surface when soil porosity of a sieved, light-textured soil decreased from 0.60 to 0.44 .

Prolonged rainfall in a period of about 3 to 5.5 weeks drastically changed soil conditions in all experiments. Depending on the amount and distribution of rainfall and drainage conditions, matric water potential temporarily increased to values above field capacity. Especially in the severely compacted soil air-filled porosity and therefore gas diffusion decreased to low values. Soil oxygen concentrations dropped from $20-21 \%$ (free air) to values lower than $10 \%$ and even lower than $5 \%$. In the arable layer of the loamy fine sand (Heeten, 1981) this situation developed gradually when the water-table was at $-1.3 \mathrm{~m}$ but did not occur in another part of the field with a $0.2 \mathrm{~m}$ deeper water-table. On the fine sandy loam (Wijhe, 1982) oxygen concentrations of the severely compacted soil were always above $10 \%$. Oxygen concentrations just below the arable layer were 3-4\% lower than in the arable layer and insufficient for root growth for some time in all experiments. A direct effect of the low oxygen concentrations was that root growth in the severely compacted soil shifted towards superficial soil layers with a more adequate aeration. This effect was very pronounced on the fine sandy soil (Heino, 1980 and Heino, 1982) and in the lower part of the experiment on loamy fine sand (Heeten, 1981). Although many roots at greater depths were yellow-brown instead of white 
direct evidence of root decay due to aeration stress was not obtained.

A direct measure for aeration stress does not exist and it is sure that many aspects (e.g. Stolzy \& Flühler, 1978) together determine the harmful effect on the crop growth and yield. Among these are the specific sensitivity of the crop and the variety, crop size and developmental stage, duration and intensity of the stress, soil and crop potential oxygen demand, the development and effect of toxic gases and the soil and environmental conditions after cessation of the stress (Brouwer \& Wiersum, 1977). In the literature only one or at most a few of these aspects are examined together in experiments with sharply defined situations simulating insufficient and fully sufficient oxygen supply to the root system (e.g. Wenkert et al., 1981). Evidently there is a lack of information on the effects of suboptimal oxygen supply on root growth and root functioning. In maize, interpretation is further complicated by adaptation processes like the formation of aerenchyma (Konings, 1983) and compensational root growth.

Combining all information we can conclude that aeration stress was clear in the experiment on fine sand in both 1980 and 1982 . In 1982 the stress period started about 3 instead of 5 weeks after emergence and had a duration of 19 instead of 29 days. Therefore, harmful effects are expected to be smaller and possibilities for compensational growth larger in 1982 than in 1980. The 1982 experiment on fine sandy loam had a weaker indication of aeration stress than the experiment on fine sand. The loamy fine sand (1981) with a slightly higher water-table had a clear, and the experiment with a slightly lower water-table, an intermediate indication of aeration stress. The stress period started in the same week as in 1980 but had a duration of 39 instead of 29 days. Stress gradually increased with time and the end of the wet period coincided with anthesis. In 1980 and 1982, anthesis occurred 2 and 3 weeks respectively after the end of the wet period. In all experiments potentially harmful effects of the aeration stress were masked by favourable soil conditions afterwards. The matric water potential at the rooting front was favourable during a long time. Aeration stress gradually shifted the soil compaction-crop response relationships established during the pre-aeration stress period towards optimum growth in less compacted soil. The non-compacted soil stayed behind the optimum density for a considerable period of time but differences gradually disappeared later on. Crop senescence started earlier only in cases with a clear aeration deficiency.

The question is to which extent the results of these experiments are in line with the concept proposed in a previous paper (Boone et al., 1986). Central in this concept is that the range of soil structures which does not, partly or fully restrict root growth and root functioning with respect to soil aeration and mechanical impedance, depends on soil matric water potential (Fig. 2). The lower the potential which (partly) restricts aeration and the higher the potential which restricts root growth mechanically, the narrower the range of favourable conditions. Aeration stress was the dominating factor and therefore the matric water potential at the boundary between non-restrictive and partly restrictive for aeration was taken as 100 and the potential at the boundary between partly and fully restrictive as 0 . The actual mean matric water potential in the arable layer during the period with aeration stress was expressed as a percentage of this range. This percentage is called 'aeration index'. 


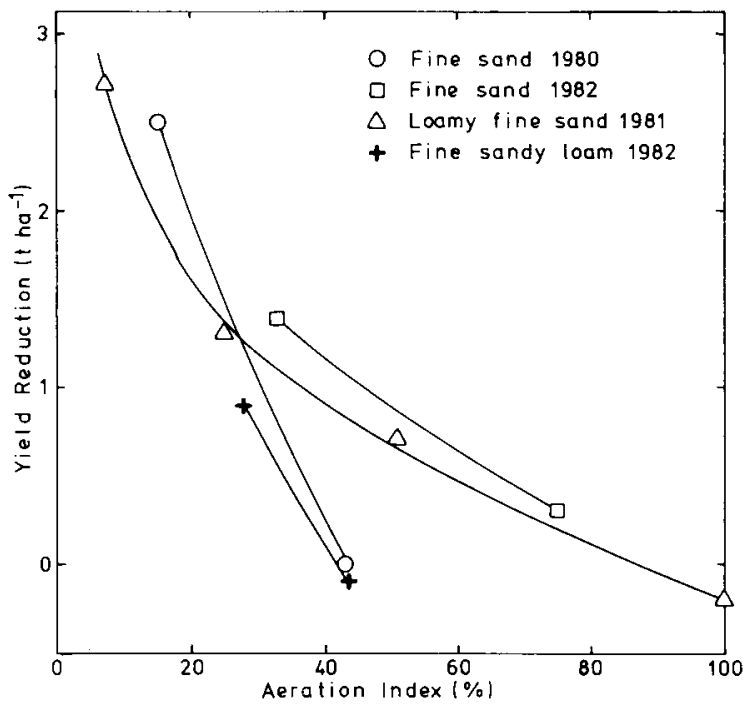

Fig. 3. Reduction in dry matter yield of moderately and severely compacted soil compared with lightly compacted soil in relation to the soil aeration index (see text).

The final dry matter yield of the lightly compacted soil in each experiment was taken as reference and the reduction in yield of the moderately and severely compacted soil was related to this aeration index (Fig. 3). Yield losses increased curvilinear to substantial values at low indices. In view of the fact that many aspects together determine the ultimate effect, agreement between experiments is reasonably good. At crop emergence soil oxygen consumption in Heino 1982 was much higher than in Wijhe 1982. It therefore seems understandable that the first experiment had a higher susceptibility for aeration stress than the second. Yield reductions of less than $1 \mathrm{t} \mathrm{ha}^{-1}$ which is equivalent to about $6 \%$ of the yield were not statistically significant so it may be concluded that the non-restrictive to partly restrictive aeration boundary was too high. Further improvements can be expected if the aeration limits can be calculated more accurately by knowledge about actual oxygen demands during crop growth and crop responses due to suboptimal aeration conditions. Moreover, the frequency, time span and extent to which the aeration limits are exceeded should be known more exactly.

\section{Conclusions}

1. Crop responses to changes in soil structure induced by tillage and field traffic have a dynamic character and largely depend on the level and variability in time of climate, soil and drainage conditions and crop demands.

2. The approach to relate potential risks for root growth and root functioning of a range of soil structures to matric water potential seems promising in predicting risks for plant growth under specific circumstances. 
3. Yields of maize for silage and soil density of sandy soil were related by flat optima with small yield reductions at the loose end and large yield reductions at the dense side caused by insufficient soil aeration. Small changes in one of the decisive factors had a large impact on the results.

\section{References}

Boone, F. R., H. M. G. van der Werf, B. Kroesbergen, B. A. ten Hag \& A. Boers, 1986. The effect of compaction of the arable layer in sandy soils on the growth of maize for silage. 1. Critical matric water potentials in relation to soil aeration and mechanical impedance. Netherlands Journal of Agricultural Science 34: 155-171.

Brouwer, R. \& L. K. Wiersum, 1977. Root aeration and crop growth. In: U. S. Gupta (Ed.), Crop physiology, Vol. 2, p. 157-201. Oxford University Press.

Konings, H., 1983. Formation of gas spaces (aerenchyma) in seedling roots of Zea mays L. under aerated and non-aerated conditions. In: W. Böhm, L. Kutschera \& E. Lichtenegger (Eds), Root ecology and its practical application, p. 761-765. Bundesanstalt für alpenländische Landwirtschaft, Irdning, Federal Republic of Germany.

Stolzy, L. H. \& H. Flühler, 1978. Measurement and prediction of anaerobiosis in soils. In: D. R. Nielson \& J. G. McDonald (Eds), Nitrogen in the environment, Vol. 1, p. 363-426. Academic Press, New York.

Wenkert, W., N. R. Fausey \& H. D. Watters, 1981. Flooding responses in Zea mays L. Plant and Soil 62: $351-366$.

\section{Erratum to the previous paper}

In our previous paper (Boone et al., 1986) for the diffusion of oxygen in air $\left(D_{0}\right)$ should be read: $D_{0}=2.01 \times 10^{-5} \mathrm{~m}^{2} \mathrm{~s}^{-1}$ instead of $D_{0}=0.201, D / D_{0}=0.015$ instead of $15 \times 10^{-7} \mathrm{~m}^{2} \mathrm{~s}^{-1}$ at the Upper Critical Aeration Limit and $D / D_{0}=7.5 \times 10^{-4}$ instead of $7.5 \times 10^{-8} \mathrm{~m}^{2} \mathrm{~s}^{-1}$ at the Lower Critical Aeration Limit. Figures in some columns of Table 5 in which $D_{0}$ appears should also be corrected. 